Journal of Computer Science 8 (9): 1422-1427, 2012

ISSN 1549-3636

(C) 2012 Science Publications

\title{
Decoupling and Linearizing of a pH Plant using Hirschorn's and Genetic Algorithms
}

\author{
${ }^{1}$ Subbulekshmi, D. and ${ }^{2}$ J. Kanakaraj \\ ${ }^{1}$ Department of Instrumentation and Control Systems Engineering, \\ ${ }^{2}$ Department of Electrical and Electronics Engineering, \\ PSG College of Technology, Coimbatore-641004, India
}

\begin{abstract}
Problem statement: This study is to maintain the interacting liquid level and $\mathrm{pH}$ parameter at a desired value. The purpose of decoupling and linearization algorithm is to prevent interaction and making the system linear. Approach: In this study Hirchorn's and Genetic Algorithms (GA) are proposed to make the system linear, non interacting system. This study presents the performance comparison of Hirschorn's (decoupling and linearization algorithm) and Genetic Algorithms (GA) for a approximated model of Interacting level and $\mathrm{pH}$ non-linear process. Results: Closed loop simulation was carried out incorporating the above algorithm and the results are compared. Control performance with Hirschorn's is found to give better results than with GA. Conclusion: This study demonstrates the effectiveness of Hirchorn's algorithm in MIMO nonlinear interacting process. Obtained control laws for Hirschorn's algorithm give improved values for Settling Time (Ts) and Integral Square Error (ISE).
\end{abstract}

Key words: Genetic algorithm, Hirschorn's algorithm, multivariable process control, PID controller

\section{INTRODUCTION}

The nonlinear, strongly interacting nature of multivariable chemical processes necessitates the development of solid control methodologies that are capable of coping with both nonlinearities and interactions. Most of the chemical processes possess nonlinear dynamic characteristics. The traditional approach to design controllers for a non-linear process is to linearize the process model around its steady state operating point and to apply the linear control theory to it. However this control theory is developed under the assumption that the process model is known exactly (Chien et al., 2008). Therefore if there is a difference between the real process and the process model, application of this theory will give unsatisfactory results. The degree of the mismatch is not high in many chemical processes. Control of $\mathrm{pH}$ is important in the chemical industry especially in waste water treatment. However $\mathrm{pH}$ processes are difficult to control due to their nonlinear dynamics. In a chemical process involving the mixing of reaching streams (acid, base, salts), the $\mathrm{pH}$ is a measure of the hydrogen ion concentration, which determines the acidity/alkaline of a solution.

Kalafatis et al. (2005) proposed a control strategy which is called the Multi Input/Multi Output (MIMO) globally linearizing control. For SISO systems, input output linearization is done and linearizing state feedback can be obtained by explicit formulas through it. Then this state feedback law is applied to a nonlinear process and an external controller with integral action can be used for set point tracking and rejection of disturbances. The resulting control structure is called the Globally Linearizing Control (GLC) structure. This methodology is tried here for an MIMO nonlinear system having equal number of inputs and outputs.

The non-linear system is considered with identical number of inputs and outputs Eq. 1 and 2:

$$
\begin{aligned}
& \dot{x}=f(x)+g(x) u \\
& y=h(x)
\end{aligned}
$$

Where:

$$
\begin{aligned}
\mathrm{x}= & \text { The state vector of dimension } \mathrm{n} \\
\mathrm{u}= & \text { An input vector of dimension } \mathrm{m} \\
\mathrm{y}= & \text { An output vector of dimension of } \mathrm{p} \\
\mathrm{f}(\mathrm{x})= & \mathrm{A} \text { smooth function } \\
\mathrm{h}(\mathrm{x})= & \mathrm{A}(\mathrm{p}, 1) \text { vector with a row element } \mathrm{h}_{\mathrm{j}}(\mathrm{x}) \text { also } \mathrm{a} \\
& \text { smooth function } \\
\mathrm{g}(\mathrm{x})= & \text { An }(\mathrm{n}, \mathrm{m}) \text { matrix with elements of each column } \\
& \text { being } \mathrm{g}_{\mathrm{j}}(\mathrm{x})
\end{aligned}
$$


Complex processes often have several variables (outputs) that we wish to control and several manipulated inputs to provide the control. Consider a plant with $\mathrm{m}$ output variables $\mathrm{y}_{1}, \mathrm{y}_{2}, \ldots \ldots \ldots \mathrm{y}_{\mathrm{m}}$ and $\mathrm{m}$ control variables, $\mathrm{u}_{1}, \mathrm{u}_{2}, \ldots \ldots . . \mathrm{u}_{\mathrm{m}}$. A mathematical model of this system is therefore an $\mathrm{m} \mathrm{x} \mathrm{m}$ transfer function matrix as defined below:

$$
\mathrm{Y}(\mathrm{s})=\mathrm{G}(\mathrm{s}) \mathrm{U}(\mathrm{s})
$$

Or:

$$
\left[\begin{array}{c}
\mathrm{Y}_{1}(\mathrm{~s}) \\
\mathrm{Y}_{2}(\mathrm{~s}) \\
\bullet \\
\bullet \\
\mathrm{Y}_{\mathrm{m}}(\mathrm{s})
\end{array}\right]=\left[\begin{array}{ccccc}
\mathrm{G}_{11}(\mathrm{~s}) & \mathrm{G}_{12}(\mathrm{~s}) & \bullet & \bullet & \mathrm{G}_{1 \mathrm{~m}}(\mathrm{~s}) \\
\mathrm{G}_{21}(\mathrm{~s}) & \mathrm{G}_{22}(\mathrm{~s}) & \bullet & \bullet & \mathrm{G}_{2 \mathrm{~m}}(\mathrm{~s}) \\
\bullet & & & & \bullet \\
\bullet & & & & \bullet \\
\mathrm{G}_{\mathrm{m} 1}(\mathrm{~s}) & \mathrm{G}_{\mathrm{m} 2}(\mathrm{~s}) & \bullet & \bullet & \mathrm{G}_{\mathrm{mm}}(\mathrm{s})
\end{array}\right]\left[\begin{array}{c}
\mathrm{U}_{1}(\mathrm{~s}) \\
\mathrm{U}_{2}(\mathrm{~s}) \\
\bullet \\
\bullet \\
\mathrm{U}_{\mathrm{m}}(\mathrm{s})
\end{array}\right]
$$

An important general property of such systems is interaction (or coupling) between inputs $\mathrm{U}_{\mathrm{i}}$ and outputs $\mathrm{Y}_{\mathrm{i}}$ in the sense that any input $\mathrm{U}_{\mathrm{i}} 1 \leq \mathrm{i} \leq \mathrm{m}$, will have a dynamic effect on all the outputs $Y_{i}, 1 \leq j \leq m$. If each input $U_{i}$ has a dynamic effect only on $Y_{i}$, the system is said to be non-interacting ( or decoupled).

A multivariable nonlinear system of the form of Eq. 1 is called input/output linearizable. If there exists a static feedback of the form (2), feedback law Eq. 3:

$\mathrm{u}=\mathrm{P}(\mathrm{x})+\mathrm{Q}(\mathrm{x}) v$

where, $\mathrm{Q}(\mathrm{x})=$ non singular and linear vector differential operators of the form Eq. 4:

$$
\mathrm{L}_{\zeta \mathrm{i}}=\sum_{\mathrm{k}=0}^{\mathrm{\zeta i}} \beta_{\mathrm{ik}} \frac{\mathrm{d}^{\mathrm{k}}}{\mathrm{dt}^{\mathrm{k}^{\mathrm{i}}}} \mathrm{i}=1, \ldots \ldots . . \mathrm{m}
$$

With constant coefficient $\beta_{\mathrm{ik}}=\left[\beta_{\mathrm{ik}}^{1} \beta_{\mathrm{ik}}^{2} \ldots . \beta_{\mathrm{ik}}^{\mathrm{m}}\right]^{\mathrm{T}} \in \mathrm{R}^{\mathrm{m}}$ satisfying $\beta_{\text {içi }} \neq 0$ and Eq. 5:

$$
\operatorname{det}\left[\left(\sum_{\mathrm{k}=0}^{\varsigma_{1}} \beta_{1 \mathrm{k}} \mathrm{s}^{\mathrm{k}}\right)\left(\sum_{\mathrm{k}=0}^{\varsigma_{2}} \beta_{2 \mathrm{k}} \mathrm{s}^{\mathrm{k}}\right) \ldots \ldots .\left(\sum_{\mathrm{k}=0}^{\varsigma_{\mathrm{m}}} \beta_{\mathrm{mk}} \mathrm{s}^{\mathrm{k}}\right) \neq 0\right.
$$

Such that Eq. 6:

$$
\sum_{\mathrm{i}=1}^{\mathrm{m}} \mathrm{L}_{\mathrm{ci}} \mathrm{y}_{\mathrm{i}}=\mathrm{v}
$$

If a system gets input/output linearized by state feedback in the sense of the above definition, it may be convenient to think of the closed loop system in the laplace domain. The matrix fraction description of the closed loop system linearised by state feedback is given as Eq. 7 and 8:

$$
\mathrm{y}(\mathrm{s})=[\mathrm{B}(\mathrm{s})]^{-1} \mathrm{v}(\mathrm{s})
$$

Where:

$$
\mathrm{B}(\mathrm{s})=\left[\left(\sum_{\mathrm{k}=0}^{\varsigma_{1}} \beta_{1 \mathrm{k}} \mathrm{s}^{\mathrm{k}}\right)\left(\sum_{\mathrm{k}=0}^{\varsigma_{2}} \beta_{2 \mathrm{k}} \mathrm{s}^{\mathrm{k}}\right) \ldots \ldots .\left(\sum_{\mathrm{k}=0}^{\varsigma_{\mathrm{m}}} \beta_{\mathrm{mk}} \mathrm{s}^{\mathrm{k}}\right)\right]
$$

In a well formulated control problem all outputs $\mathrm{y}_{\mathrm{i}}$ must possess relative order, so that the system is output controllable.

From Kravaris and Soroush (1990) the necessary condition for input/output linearizability is that all the outputs must have relative order. Also the sufficient condition for input/output linearizability is that the system should possess relative orders and the characteristic matrix be nonsingular.

In order to characterize the class of input/output linearizable systems, one needs conditions which are both necessary and sufficient.

\section{MATERIALS AND METHODS}

Development of Hirschorn's control law: In order to calculate a control law that induces linear input/ output behavior in the MIMO system Hirschorn's algorithm is tried. It helps to find a differential operator such that, when applied to the outputs, it will provide a set of algebraic expressions in ' $x$ ' and ' $u$ ' that are solvable for ' $u$ '.

The control law allows controlling linear systems without having to impose any structural constraints on the closed-loop dynamics of the system. The control designer has, therefore, the flexibility to adjust the parameters $\beta_{\mathrm{ik}}$, for fast closed-loop dynamics and desirable level of coupling.

From (Kravaris and Soroush 1990), if Eq. 9:

$\varsigma^{\left(\mathrm{k}^{*}\right)}=\mathrm{m}$

$\mathrm{F}_{1}(\mathrm{x})=$ constant, $1=0, \ldots \ldots . \mathrm{K}^{*}-1$ then the systems Eq. 1 is input/output linearizable. Further more given $\mathrm{m} \times 1$ matrices $\beta_{\mathrm{ik}}, \mathrm{i}=0, \ldots \ldots . \mathrm{m}, \mathrm{k}=0, \ldots \ldots . . \mathrm{r}_{\mathrm{i}}-1$ $\mathrm{mx}\left(\mathrm{m}-\varsigma^{(0)}\right), \operatorname{mx}\left(\mathrm{m}-\varsigma^{(1)}\right), \ldots . . \mathrm{mx}\left(\mathrm{m}-\varsigma^{\left(\mathrm{k}^{*}-1\right)}\right)$ matrices $\gamma_{0}$, $\gamma_{1}, \ldots \ldots . \gamma^{*}-1$ and an $\mathrm{m} x \mathrm{~m}$ invertible matrix $\Gamma$.

The state feedback law as given in (2) is reproduced below Eq. 10: 


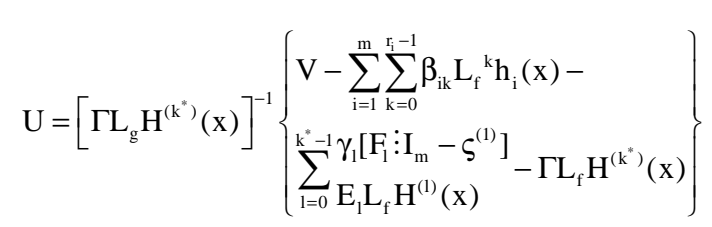

Applying Hirschorn's linearising algorithm, the decoupling and linearization control law obtained from the state feedback, is given as Eq. 11 and 12:

$$
\begin{aligned}
& \mathrm{U}_{1}=\frac{\mathrm{S}}{(\mathrm{CAO}+\mathrm{CBO})}\left[\mathrm{bV}_{1}-\mathrm{b} \zeta_{10} \mathrm{x}_{1}+\mathrm{b} \frac{\mathrm{k}}{\mathrm{s}} \mathrm{x}_{1}^{1 / 2}-\right. \\
& \frac{\mathrm{bk}^{2}}{2 \mathrm{~S}^{2}}+\mathrm{CBOV}_{1}-\mathrm{CBO} \zeta_{10} \mathrm{x}_{1}+\mathrm{CBO} \frac{\mathrm{k}}{\mathrm{s}} \mathrm{x}_{1}^{1 / 2}- \\
& \left.\mathrm{CBO} \frac{\mathrm{k}^{2}}{2 \mathrm{~S}^{2}}+\mathrm{x}_{1} \log _{10}(a) \mathrm{V}_{2}-\mathrm{x}_{1} \log _{10}(a) \zeta_{20} \mathrm{x}_{2}\right] \\
& \mathrm{U}_{2}=\frac{\mathrm{S}}{(\mathrm{CAO}+\mathrm{CBO})}\left[-\mathrm{bV}_{1}+\mathrm{b} \zeta_{10} \mathrm{x}_{1}\right. \\
& -\mathrm{b} \frac{\mathrm{k}}{\mathrm{s}} \mathrm{x}_{1}^{1 / 2}+\frac{\mathrm{bk}}{2 \mathrm{~S}^{2}}+\mathrm{CBO} \mathrm{V}_{1}-\mathrm{CAO} \zeta_{10} \mathrm{x}_{1} \\
& +\mathrm{CAO} \frac{\mathrm{k}}{\mathrm{s}} \mathrm{x}_{1}^{1 / 2}-\mathrm{CAO} \frac{\mathrm{k}^{2}}{2 \mathrm{~S}^{2}}-\mathrm{x}_{1} \\
& \left.\log _{10}(\mathrm{a}) \mathrm{V}_{2}+\mathrm{x}_{1} \log _{10}(\mathrm{a}) \zeta_{20} \mathrm{x}_{2}\right]
\end{aligned}
$$

Substituting $\mathrm{U}_{1}$ and $\mathrm{U}_{2}$ in the state model, results in state equation being in decoupled form and linearised form. The advantage of using Hirschorn's algorithm is that the control law is less complex. Further one gets more dynamic acid feed flow rate of liquid $\mathrm{U}_{1}$ and base flow rate of liquid $\mathrm{U}_{2}$ than possible with kravaris algorithm and also the simulation results show that Hirschorn's algorithm has better time domain characteristics as illustated is Table 1. Substituting $\mathrm{U}_{1}$ and $\mathrm{U}_{2}$ in the state model, results in state equation being in decoupled form and linearised form. Substituting $\mathrm{U}_{1}$ and $\mathrm{U}_{2}$ in Eq. 13 and 14:

$\dot{\mathrm{x}}_{1}=\mathrm{V}_{1}-\delta_{10} \mathrm{x}_{1}-\frac{\mathrm{k}^{2}}{2 \mathrm{~s}^{2}}$

$$
\dot{\mathrm{x}}_{2}=\mathrm{V}_{2}-\delta_{20} \mathrm{x}_{1}
$$

Development of genetic algorithm: Genetic Algorithm (GA) is a stochastic global search method that mimics the process of natural evolution. It is a class of probabilistic optimization algorithms using concepts of "Natural Selection" and "Genetic Inheritance" and is originally developed by Hassanzadeh et al. (2008). Genetic algorithm starts with no knowledge of the correct solution and depends entirely on responses from its environment and evolution operators (i.e. reproduction, crossover and mutation) to arrive at the best solution. GA repeatedly modifies a population of individual solutions (Tan et al., 2005).

Initialization of GA parameters: To start with GA, population size, bit length of chromosome, number of iterations, selection, crossover and mutation methods need to be defined. Selection of these parameters decides, to a great extent, the ability of the designed controller. Higher the population size higher diversity and thus better convergence. But this needs more execution time; therefore a population size of 100 is used in simulation. Chromosome length selection also is a compromise between accuracy and simulation time.

Genetic operations: Normalized geometric selection is the primary selection process involved in this study. A uniform mutation is employed for the sake of simplicity. The Arithmetic crossover procedure is specifically used for floating point numbers and it is the ideal one point cross over option for the use. During the initial stages, it is expected that crossover probability $\mathrm{Pc}(\mathrm{i})$ is larger, in order to optimize whole population effectively; whereas, in the later stages, a smaller Pc(i) value is better to avoid destroying the optimization performance.

Objective function and fitness value: The most crucial step in applying GA is to choose the objective functions that are used to evaluate fitness of each chromosome. The performance indices frequently used are Integral of Time multiplied by Absolute Error (ITAE), Integral of Absolute Magnitude of the Error (IAE), Integral of the Square of the Error (ISE) and Mean of the Square of the Error (MSE). GA is used to minimize the value of these performance indices and because of the fact that the smaller the value of performance indices of a chromosome, the fitter the chromosome will be and vice versa.

Termination criterion: A termination method is involved that stops the evaluation when the fitness is deemed as converged.

In $n \times n$ multivariable process, the algorithms with controllers would be used in the $\mathrm{n}$ loops associated with the process is shown in Fig. 1.

A performance comparison between two classes of search algorithms is presented in this study. The algorithms are applied to improve the performance of the non-linear MIMO process. In this study generation gap of 0.9. Single point cross over and good convergence 
achieved for the generation less than 40.12 bit string elements are used for the encoding of each of the 2 parameters. Cross over and mutation probability was chosen to be 0.45 and 0.001 respectively.

Application to chemical process control: The Level and $\mathrm{pH}$ control process is shown schematically in Fig. 2, adopting parameters from Kravaris and Chung (1987), process model is Eq. 15 and 16:

$$
\begin{aligned}
& \dot{\mathrm{x}}_{1}=\left(\frac{-\mathrm{k}}{\mathrm{s}}\right) \mathrm{x}_{1}^{1 / 2}+\frac{1}{\mathrm{~s}}\left(\mathrm{U}_{1}+\mathrm{U}_{2}\right) \\
& \dot{\mathrm{x}}_{2}=\left[\frac{-1}{\mathrm{sx}_{1} \log _{10}(\mathrm{a})}\right]\left[(\mathrm{b}-\mathrm{CA} 0) \mathrm{U}_{1}+(\mathrm{b}+\mathrm{CB} 0) \mathrm{U}_{2}\right]
\end{aligned}
$$

Where:

$$
\begin{aligned}
& \mathrm{a}=\Xi\left(\mathrm{x}_{2}\right)=-10^{\mathrm{x}_{2}-14}+10^{-\mathrm{x}_{2}} \\
& \mathrm{~b}=\eta\left(\mathrm{x}_{2}\right)=10^{\mathrm{x}_{2}-14}+10^{-\mathrm{x}_{2}}
\end{aligned}
$$

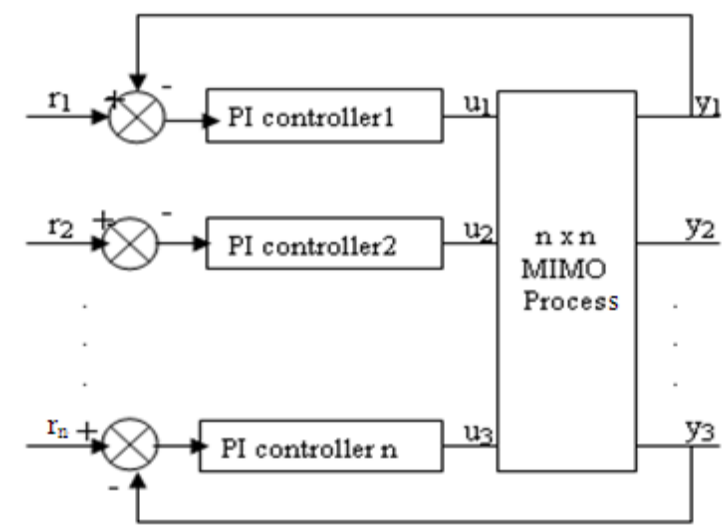

Fig. 1: $\mathrm{n} \times \mathrm{n}$ multivariable process

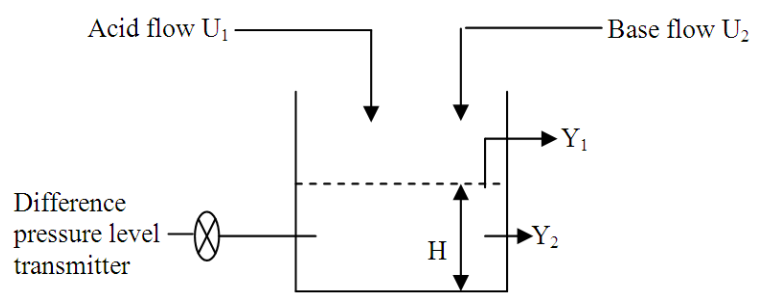

Fig. 2: Schematic Diagram for the level and $\mathrm{pH}$ control process. (a) $\mathrm{U}_{1}$ is the feed flow rate of acid (b) $\mathrm{U}_{2}$ is the feed flow rate of base (c) $\mathrm{Y}_{1}$ is the level sensor output (d) $\mathrm{Y}_{2}$ is the $\mathrm{pH}$ sensor output. (e) $\mathrm{H}$ is the height of the liquid
Output equations are:

$$
\begin{aligned}
& \mathrm{y}_{1}=\mathrm{x}_{1} \\
& \mathrm{y}_{2}=\mathrm{x}_{2}
\end{aligned}
$$

Here $\mathrm{x}_{1}$ and $\mathrm{x}_{2}$ are the liquid level and the values of $\mathrm{pH}$ respectively. $\mathrm{u}_{1}$ and $\mathrm{u}_{2}$ are feed flow rate of strong acid and strong base respectively.

The tank is a stirred column of $75 \mathrm{~cm}$ height and $15.6 \mathrm{~cm}$ diameter. A strong acid (HCL) at a concentration $\mathrm{CAO}$ and strong base $(\mathrm{NaOH})$ at concentration CB0. The aim of this control process is to keep the liquid level and the $\mathrm{pH}$ at the desired values. It is known that this control problem is very difficult when the setpoint is nearer to the point of neutrality.

The values ' $s$ ' and ' $k$ ' are cross sectional area of the tank $191 \mathrm{~cm}^{2}$ and constant coefficient $1.8 \mathrm{~cm}^{12} \mathrm{~s}^{-1}$. The feed concentrations are $\mathrm{CAO}=\mathrm{CB} 0=0.03 \mathrm{~mol} \mathrm{~cm}$. The feed rates are constrained as $0<=u_{1}, \quad u_{2}<=22$ $\mathrm{cm}^{3} \mathrm{~s}^{-1}$.

Simulations are carried out and closed loop response is obtained. The performance of the proposed algorithm was evaluated by extensive numerical simulations (Mwembeshi et al., 2004; Kalafatis et al., 2005). A standard Runga-Kutta Gill algorithm was used for the numerical integration of the set of ordinary differential equations. In order prevent numerical conditioning problem, all equations were first appropriately non dimensionalized. Prior to application of the developed algorithm, there was good coupling between level and $\mathrm{pH}$ on both $\mathrm{u}_{1}$ and $\mathrm{u}_{2}$. Application of the algorithm developed effectively eliminated the interaction and achieved a good decoupling between the two. Now it is decoupled and interaction is eliminated.

\section{RESULTS}

Utilizing the model given by ref (Chien et al., 2008), Hirschorn's algorithm with controller was designed. Simulation was carried out for two differential controllers. The controllers used are PI and PI-SPW.

\section{DISCUSSION}

At first the simulations without decoupling with PI controller were carried out to examine the influence of the modeling errors. Figure 3 shows the output response of the level and $\mathrm{pH}$ when the set point of the level was changed from $1-40 \mathrm{~cm}$ and $\mathrm{pH}$ from $1-5$. 


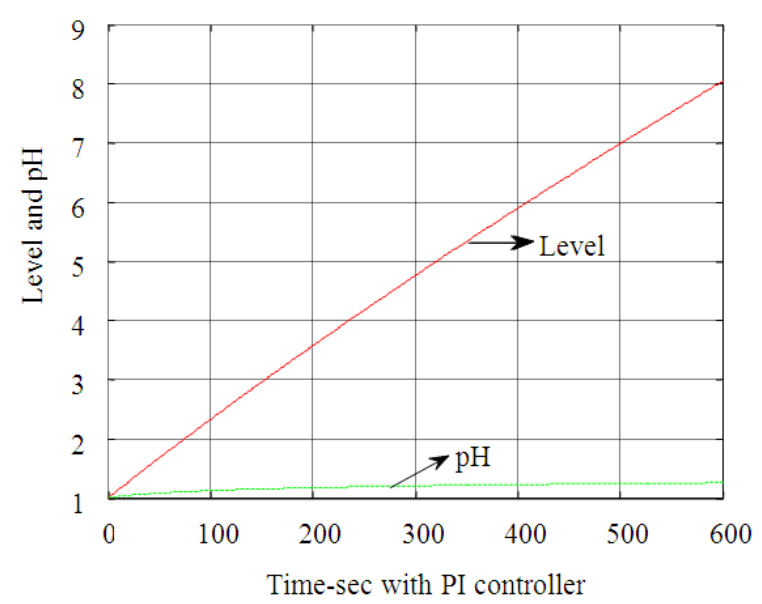

Fig. 3: Process without decoupling with PI controller

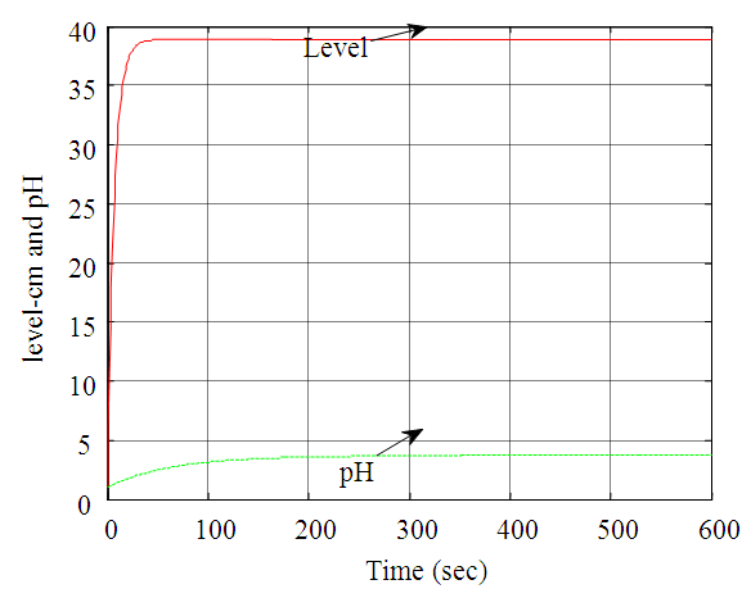

Fig. 4: Process with decoupling (hirs) with PI controller

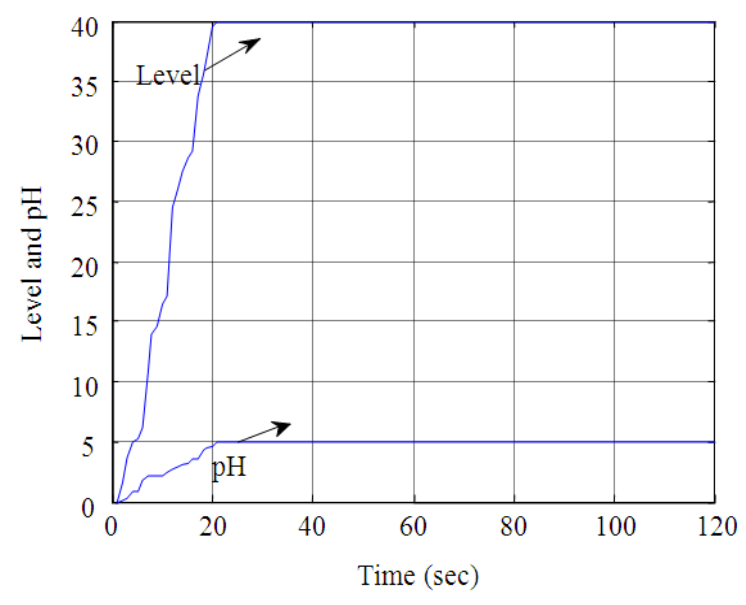

Fig 5:Output response for the step change in the level with GA
Table 1: Comparision of Ts and ISE using algorithms

\begin{tabular}{llll}
\hline Algorithm & & Ts & ISE \\
\hline Hirschorn's & Level & 10 & $287 \mathrm{e}+002$ \\
& pH & 10 & 40.109 \\
GA & Level & 20 & $9.12 \mathrm{e}+004$ \\
& pH & 22 & $1.1 \mathrm{e}+003$ \\
\hline
\end{tabular}

In the next step PI controller (Mwembeshi et al., 2004; Kalafatis et al., 2005) was added along with the Hirchorn's algorithm, the corresponding response is shown in Fig. 4. The sudden disturbance introduced at time of $200 \mathrm{sec}$ in level was not affecting the $\mathrm{pH}$ process. It can be seen from the figure that under the influence of the controller performance, ISE has improved than in Fig. 3.

The same model is utilized for simulation by applying Genetic algorithms (Son et al., 2004). Results obtained are shown in Fig. 5. The sudden disturbance introduced at time of $200 \mathrm{sec}$ in level was not affecting the $\mathrm{pH}$ process. It can be seen from the figure that the introduction of the Hirschorn's control, performance criteria ISE is improved in Fig. 4 than Fig. 5.

\section{CONCLUSION}

The Hirschron's algorithm was applied to a nonlinear MIMO chemical process. The simulation results show that even if the processes are non-linear and interactive and modeling errors are present, a satisfactory control performance could be obtained.

This study reports the simulation application of the Hirschorn's control law and GA to the chemical process, (level and $\mathrm{pH}$ control process). Simulation approach for a multivariable process using Hirschorn's (decoupling and linearization algorithm) with PI controller and GA algorithm has been studied. Results of these simulations are presented in Table 1. This indicates that the Hirschorn's algorithm gives less settling time and integral square error for both level and $\mathrm{pH}$ parameter.

\section{REFERENCES}

Chien, T., C.C. Chen, Y.C. Huang and W.J. Lin, 2008. Stability and almost disturbance decoupling analysis of nonlinear system subject to feedback linearization and feedforward neural network controller. IEEE Trans. Neural Netw., 19: 12201230. DOI: 10.1109/TNN.2008.2000207

Hassanzadeh, I., S. Mobayen and A. Harifi, 2008. Input-Output Feedback Linearization Cascade Controller Using Genetic Algorithm for Rotary Inverted Pendulum System. Am. J. Applied Sci., 5: 1322-1328. DOI: 10.3844/ajassp.2008.1322.1328 
Kalafatis, A.D., L. Wang and W.R. Cluett, 2005. Linearizing feedforward-feedback control of $\mathrm{pH}$ processes based on the Wiener model. J. Process. Control, 15: 103-112. DOI: 10.1016/j.jprocont.2004.03.006

Kravaris, C. and C.B. Chung, 1987. Nonlinear state feedback synthesis by global input/output linearization. AIChE J., 33: 592-603. DOI: 10.1002/aic.690330408

Kravaris, C. and M. Soroush, 1990. Synthesis of multivariable nonlinear controllers by input/output linearization. AIChE J., 36: 249-264. DOI: 10.1002/aic.690360211

Mwembeshi, M.M., C.A. Kent and S. Salhi, 2004. A genetic algorithm based approach to intelligent modelling and control of $\mathrm{pH}$ in reactors. Comput. Chem. Eng., 28: 1743-1757. DOI: 10.1016/j.compchemeng.2004.03.002
Son, J.S., D.M. Lee, I.S. Kim and S.K. Choi, 2004. A study on genetic algorithm to select architecture of a optimal neural network in the hot rolling process. J. Mater. Proces. Technol., 153-154: 643-648. DOI: 10.1016/j.jmatprotec.2004.04.376

Tan, W.W., F. Lu, A.P. Loh and K.C. Tan, 2005. Modeling and control of a pilot $\mathrm{pH}$ plant using genetic algorithm. Eng. Appli. Artif. Intell., 18: 485-494. DOI: 10.1016/j.engappai.2004.11.006 